\section{Trends in socioeconomic inequalities in the prevalence of functional dentition among older people in Brazil}

\author{
Tendências em desigualdades na prevalência da \\ dentição funcional em idosos brasileiros
}

Tendencias en inequidades socioeconómicas,
relacionadas con la prevalencia de dentición
funcional, entre adultos mayores en Brasil
Fabiola Bof de Andrade 1

Jose Leopoldo Ferreira Antunes 2

\begin{abstract}
The objective of this research was to evaluate trends in socioeconomic inequalities in the prevalence of functional dentition among community-dwelling older adults in Brazil. This was a cross-sectional study with data from the last two SBBrasil Project surveys conducted in 2003 and 2010. Functional dentition was defined as the presence of 20 or more natural teeth and was assessed during the clinical examination of dentition status. Schooling was used as the socioeconomic position measure. Socioeconomic inequality was measured using two complex measures; the slope index of inequality (SII) and the relative index of inequality $(R I I)$. The prevalence of functional dentition was 10.8\% (95\%CI: 8.1-14.2) in 2003 and 13.6\% (95\%CI: 11.1-16.5) in 2010. The prevalence of functional dentition increased significantly over the educational rank in both years. Absolute inequalities were significant for both years and remained unaltered between 2003 and 2010. Significant relative inequality in the prevalence of functional dentition was found in both years of the survey. Socioeconomic inequalities in the prevalence of functional dentition among older adults in Brazil persisted significantly between both national oral health surveys.
\end{abstract}

Oral Health; Inequalities; Social Class

\author{
Correspondence \\ F. B. Andrade \\ Instituto René Rachou, Fundação Oswaldo Cruz. \\ Av. Augusto Lima 1715, Belo Horizonte, MG \\ 30190-002, Brasil. \\ fabiola.andrade@minas.fiocruz.br \\ 1 Instituto René Rachou, Fundação Oswaldo Cruz, \\ Belo Horizonte, Brasil. \\ 2 Faculdade de Saúde Pública, Universidade de São Paulo, \\ São Paulo, Brasil.
}




\section{Introduction}

Severe tooth loss affects $2 \%$ of the global population and ranks much higher among individuals over 60 years old, for whom it is the main cause of disability adjusted life-years (DALYs) 1. This age group is at higher risk of oral diseases 2 and has a lower prevalence of functional dentition 3,4, defined as the presence of 20 or more teeth according to the World Health Organization (WHO) 5. This threshold is considered the minimum number of natural teeth needed to maintain function without prosthetic appliances. Lacking functional dentition negatively impacts the quality of life 6 , reduces the ability to masticate and limits dietary choices and nutrition 7,8 . The lack of functional dentition has been reported to be more prevalent among socioeconomically deprived groups 9,10,11,12.

Quantifying the magnitude and monitoring trends of socioeconomic inequalities over time is important to assess the impacts of health programs and interventions on social justice 13,14. Using complex measures is necessary because they allow standardizing the assessment of health inequalities and performing comparisons over time 14,15. Furthermore, complex measures of health inequalities consider information related to all socioeconomic strata, instead of relying on the distribution of either end, and are sensitive to changes in the distribution of the population across socioeconomic groups 13,16. Although addressing socioeconomic gradients in oral health is common, research about trends in the magnitude of these inequalities using complex measures are still scarce, especially among older individuals.

Oral health in older adults reflects the lifelong effects of dental diseases and treatments in the population and is of interest for planning appropriate interventions 5 . Specifically referring to older individuals, studies assessing complex measures of health inequalities focus on the use of dental care 17,18,19, which does not fill the knowledge gap about inequalities in the distribution of oral health conditions and how much oral health policies can reduce this outcome. Therefore, the objective of this study was to evaluate trends in socioeconomic inequalities in the prevalence of functional dentition among community-dwelling older individuals in Brazil.

\section{Methods}

This study used data from the last two SBBrasil Project surveys conducted in 2003 and 2010. Both surveys were cross-sectional studies that used a probabilistic cluster sample, considered to be representative of the country in each of the age groups recommended by the WHO 20. Study procedures and details on the sample selection were published elsewhere 21,22 . The sample for this study included information on 5,262 individuals aged 65-74 years in 2003 and 7,421 in 2010.

Data collection was conducted in the household by specifically trained and calibrated dentists. Individuals answered to a structured questionnaire containing questions on behavior and socioeconomic conditions. The participants underwent a clinical oral health examination following the standardized methodology proposed by the WHO 20.

\section{Outcome}

Functional dentition was defined as the presence of 20 or more natural teeth 5 as assessed during the clinical examination of dentition status.

\section{Assessment of socioeconomic position and other covariates}

Socioeconomic position was assessed considering schooling as categorized into three groups: 0-3 years of formal education (which is considered insufficient schooling in Brazil), 4-7 years (incomplete elementary education) and 8-11 years (complete elementary to complete high school); $12+$ years (higher education).

Other covariates included are the following: age group (64-69; 70-79 years), gender and study year (2003 or 2010). 


\section{Data analysis}

Initial data analysis included a description of the sample and an estimation of the prevalence of functional dentition in each year. Adjusted prevalence and 95\% confidence intervals (95\%CI) for functional dentition according to the educational rank were also reported.

Socioeconomic inequality in functional dentition was measured using two complex measures; the slope index of inequality (SII) and the relative index of inequality (RII). These indices are regressionbased measures that consider the whole socioeconomic distribution, rather than only comparing the two most extreme groups 16 .

A ridit score is assigned to each education category based on the midpoint of the range in the cumulative distribution of the population of participants in the given category. Individuals were cumulatively ranked from 0 to 1 according to ascending socioeconomic position, " 0 " represented the lowest education level and " 1 " represented the highest. The relative educational position variable was then entered as an independent variable in the regression model. SII is the difference in the prevalence of functional dentition (absolute inequality) and RII is the prevalence rate ratio (relative inequality), between those at the top rank (highest education level) and those at rank zero (lowest education level). A SII value greater than zero and a RII value greater than one would indicate that the prevalence of functional dentition was higher among the higher socioeconomic status group.

SII and RII were estimated by employing a generalized linear model for binomial data with identity and $\log$ link functions 23 . The model was adjusted by age and gender, considering the already known relationship of these characteristics with both oral health outcomes and socioeconomic position. Differences in socioeconomic inequalities between study years were tested by including a twoway interaction term between the inequalities indexes (SII and RII) and the study year 23 .

\section{Results}

Table 1 describes the distribution of population according to relevant covariates on demographic characteristics and socioeconomic status. Most individuals in both survey years were female, had between 64-69 years and had low level of education (less than four years of schooling). The prevalence of functional dentition was 10.8\% (95\%CI: 8.1-14.2) in 2003 and 13.6\% (95\%CI: 11.1-16.5) in 2010. After the adjustment for age, gender and education ridit scores, this increase was 37\%, but it was not statistically significant; i.e., the prevalence ratio was 1.37 (95\%CI: 0.99-1.90).

Figure 1 shows the prevalence of functional dentition for the survey years according to schooling level. The prevalence was higher among individuals with greater schooling, both in 2003 and 2010; this difference was steeper in 2010. The prevalence of functional dentition significantly increased over the educational gradient in both years (Figure 2).

However, the overall improvement in the prevalence of functional dentition was not accompanied by a reduction of inequalities in the distribution of this outcome. Table 2 shows the SII and RII according to the survey years. Absolute and relative inequalities remained almost unaltered between the surveys. The prevalence of functional dentition was nearly 9.8 (95\%CI: 2.0-17.6), greater in the top of education than in the bottom in 2003; this number increased to 15.3\% (95\%CI: 6.1-24.5) in 2010. In relative terms (RII), socioeconomic inequality was statistically significant in 2003 and in 2010, the prevalence of functional dentition was nearly three times higher among those at the top of the schooling gradient than among those at the bottom; i.e., the RII was 3.40 (95\%CI: 1.76-6.57). There was no interaction between the study year and either index of inequality (RII or SII).

\section{Discussion}

The prevalence of functional dentition among older people in Brazil ranked low, although it increased significantly from 2003 to 2010, it was not significant. This condition was unequally distributed across the socioeconomic strata, adults with less education had poorer dental status in both surveys. Although an overall improvement occurred, it was not followed by a reduction of health disparities 
Table 1

Distribution of older adults according to the prevalence of functional dentition and socio-demographic characteristics. Brazil, 2003 and 2010.

\begin{tabular}{|c|c|c|c|c|}
\hline & \multicolumn{4}{|c|}{ Survey year } \\
\hline & \multicolumn{2}{|c|}{$2003(N=5,262)$} & \multicolumn{2}{|c|}{$2010(N=7,421)$} \\
\hline & Total (\%) & $\begin{array}{l}\text { Functional dentition } \\
\quad \%(95 \% \mathrm{Cl})\end{array}$ & Total (\%) & $\begin{array}{l}\text { Functional dentition } \\
\qquad \%(95 \% \mathrm{Cl})\end{array}$ \\
\hline \multicolumn{5}{|c|}{ Age group (years) } \\
\hline $64-69$ & 57.2 & $12.8(9.8-16.5)$ * & 55.0 & $14.2(11.3-17.7)$ \\
\hline $70-79$ & 42.8 & $8.1(5.1-12.6)$ & 45.0 & $12.8(9.4-17.2)$ \\
\hline Gender & & & $\%$ & \\
\hline Male & 43.5 & $15.0(11.1-19.9)$ ** & 37.8 & $17.3(13.8-21.5)$ ** \\
\hline Female & 56.5 & $7.6(5.1-11.2)$ & 62.2 & $11.3(8.5,14.9)$ \\
\hline \multicolumn{5}{|c|}{ Schooling (years) } \\
\hline $0-3$ & 61.8 & $8.7(6.7-11.3)$ * & 40.6 & $9.4(6.5-13.3) * \star *$ \\
\hline $4-7$ & 25.0 & $13.4(9.0-19.5)$ & 37.2 & $12.7(8.8-17.9)$ \\
\hline $8-11$ & 10.9 & $13.7(6.5-26.9)$ & 15.4 & $15.9(10.2,24.1)$ \\
\hline $12+$ & 2.3 & $24.0(14.4-37.3)$ & 6.8 & $38.2(28.9-48.5)$ \\
\hline
\end{tabular}

95\%Cl: 95\% confidence interval.

* p-value $<0.05$;

** p-value $<0.001$

$* * *$ p-value $<0.0001$

\section{Figure 1}

Prevalence of functional dentition among older adults according to schooling. Brazil, 2003 and 2010.

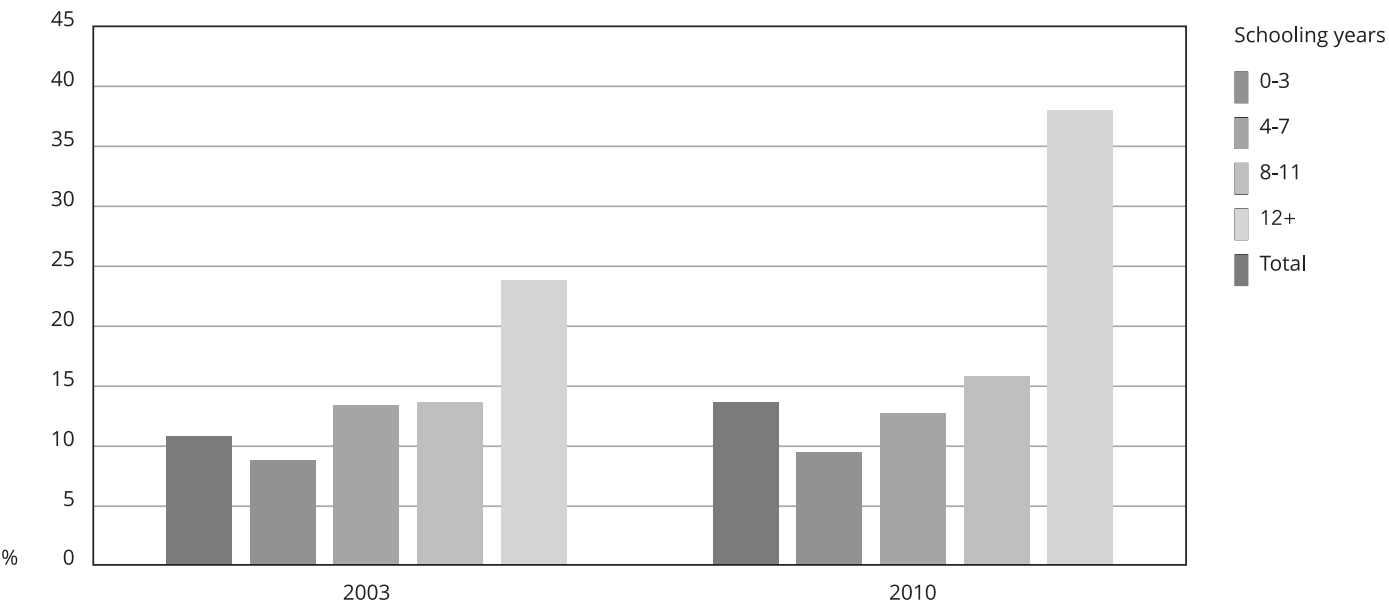




\section{Figure 2}

Predicted prevalence of functional dentition (adjusted for gender and age) according to the educational rank. Brazil, 2003 and 2010.

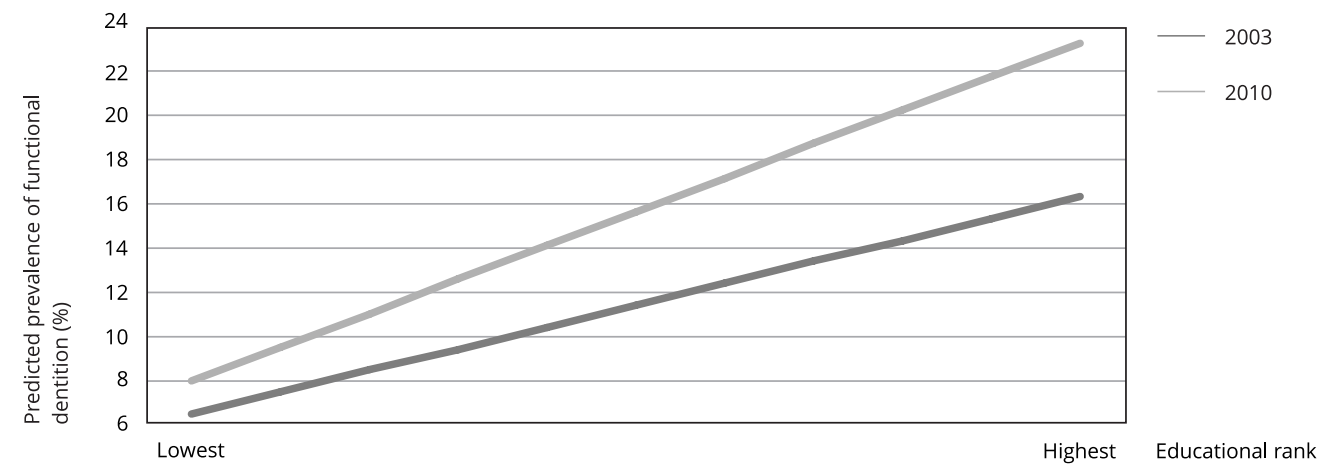

Table 2

Absolute (slope index of inequality - SII) and relative (relative index of inequalitie - RII) inequalities (adjusted for gender and age) in the prevalence of functional dentition among older adults. Brazil, 2003 and 2010.

\begin{tabular}{lcc}
\hline & SII $(95 \% \mathrm{CI})$ & RII $(95 \% \mathrm{CI})$ \\
\hline 2003 & $9.8(2.0-17.6)$ & $2.14(1.02-4.46)$ \\
2010 & $15.3(6.1-24.5)$ & $3.40(1.76-6.57)$ \\
\hline
\end{tabular}

95\%Cl: 95\% confidence interval.

in this outcome. Our results showed that there is significant absolute inequality in the prevalence of functional dentition among older adults, and that this absolute inequality remained almost unaltered between 2003 and 2010. Moreover, our results showed a significant relative inequality in the prevalence of functional dentition in both survey years. These findings are the most relevant results of this study and must be considered in the planning of health policies.

Very few studies from the literature evaluated the relevance of inequalities in the prevalence of functional dentition using these measures 10,11,12, especially among older individuals 24 . Comparisons between these results and the existing literature are difficult because the magnitude of the inequalities depends on the prevalence of the outcome 25 and how socioeconomic status was assessed 26 . This study used schooling as the socioeconomic position measure, but each measure captures different dimensions and mechanisms, which impact health outcomes 27 . Income is not a simple variable to be assessed. Actual income may not represent the lifelong socioeconomic accumulation among older individuals and in many cases, they are very similar due to retirement 28 . Moreover, schooling is closer to dental status than income, as tooth loss among this age group occurred at younger ages. Education may influence health due to its impact in improving health-related knowledge during adult life, allowing better employment opportunities which allows higher income levels and better living conditions throughout adult life 29 .

The results described here are consistent with other studies 10,12,24 that reported the presence of inequalities in the prevalence of functional dentition for other populations. Although Brazilian older individuals have suffered severe tooth lost at earlier ages, consecutive tooth loss is influenced 
by the progressive impact of dental caries risk and poor access to dental care during the life course 30 . Inequalities in these conditions are well documented in Brazil 31,32.

This study concluded that the difference in the prevalence of functional dentition across the educational strata remained practically unchanged from 2003 to 2010; concurrently with a significant increase in relative inequality. A different result was reported in Norway, a previous study observed an increase in the absolute difference of the same outcome across income strata, with the relative inequality remaining constant over the period 24. Celeste et al. 33 suggested that different time trends in the magnitude of inequalities at the population level may reflect the stage epidemiological transition of oral health and the access to dental care in these countries.

We hypothesize that the persisting absolute inequality and increasing relative inequality observed in Brazil may be explained by the long time required for improvements in tooth maintenance to reach this age group. Given that tooth loss is irreversible, older cohorts may have not benefitted yet from recent changes in behavior, access to dental care, as well as oral health policies and plans ${ }^{13}$. Considering the cohort effect, a reduction in edentulism among older adults in Brazil is expected for 205034.

In Brazil, public water fluoridation and universal access to dental care were largely implemented after the 1980s as a strategy to reduce the prevalence of dental caries, causing positive effects in reducing socioeconomic inequalities in the access to dental care 35 . However, given our results, these policies may have impacted younger age groups the most and had few repercussions to the older population. Despite the increase in access to public dental care services (free-of-charge) in Brazil, the pro-rich orientation of dental visits continues to affect the Brazilian population 32, which reinforces the need to direct more public health services and resources to prevent tooth loss in adults and older adults of poorer socioeconomic status, since the prevalence of functional dentition is lower in this group.

The persistence of socioeconomic inequalities related to functional dentition can also be detrimental in the future, because the younger age groups are retaining their teeth longer ${ }^{34}$, and dental extractions are mainly affecting the deprived individuals 11 . The increase in health inequalities that occurs concurrently with improvements in health care may be explained by the "inverse equity hypothesis" 36 . According to it, public health interventions and programs initially reach individuals in higher socioeconomic groups and the reduction of health inequalities is observed in a later stage, when poorer groups gain greater access to the interventions. From 2003 to 2010, among the adult population (34-44 years old), an absolute reduction related to income was observed for the lack of functional dentition, whereas relative inequalities increased 11 .

This was the first study to evaluate time trends in the magnitude of inequalities in functional dentition among older individuals in Brazil, a middle-income country with one of the largest older adult population worldwide. These results are important because, for this age group, oral health is influenced by several factors during the whole life course. The use of data gathered by the two most recent Brazilian oral health surveys is an important strength of this study, because these surveys used internationally standardized protocols to perform the clinical examinations. The use of complex measures of inequalities is also a strength of the study. The main study limitation is the relatively large time span since the data gathering. However, these are the most recent national oral health surveys and the only available information with a nationally representative sample including clinical examinations. A new nationwide oral health survey is planned to be performed in 2020, which will allow the trends reported here to be confronted with subsequent information.

In summary, the results reported here suggest that socioeconomic inequalities in the prevalence of functional dentition among older adults persisted significantly and even increased relatively in Brazil. These results must guide the planning of health policies because changes in this outcome are difficult to obtain and depend on behavioral changes and access to dental care in the long term. 


\section{Contributors}

F. B. Andrade participated in the study concept and design, data analysis and interpretation and drafting of manuscript. J. L. F. Antunes contributed in data analysis and interpretation and drafting of manuscript. All authors approved the final version of the manuscript.

\section{Acknowledgments}

We would like to thank Minas Gerais State Research Foundation (FAPEMIG) and Brazilian National Research Council (CNPq) for the financial support.

\section{References}

1. Marcenes W, Kassebaum NJ, Bernabé E, Flaxman A, Naghavi M, Lopez A, et al. Global burden of oral conditions in 1990-2010: a systematic analysis. J Dent Res 2013; 92:592-7.

2. Thomson WM. Dental caries experience in older people over time: what can the large cohort studies tell us? Br Dent J 2004; 196:89-92.

3. Stock C, Jürges H, Shen J, Bozorgmehr K, Listl $\mathrm{S}$. A comparison of tooth retention and replacement across 15 countries in the over-50s. Community Dent Oral Epidemiol 2016; 44:223-31.

4. Secretaria de Vigilância em Saúde, Secretaria de Atenção à Saúde, Ministério da Saúde. Projeto SBBrasil 2010. Pesquisa Nacional de Saúde Bucal: resultados principais. Brasília: Ministério da Saúde; 2011.

5. World Health Organization. Oral health surveys: basic methods. 5th Ed. Geneva: World Health Organization; 2013.

6. Haag DG, Peres KG, Brennan DS. Tooth loss and general quality of life in dentate adults from Southern Brazil. Qual Life Res 2017; 26:2647-57.

7. Ervin RB1, Dye BA. Number of natural and prosthetic teeth impact nutrient intakes of older adults in the United States. Gerodontology 2012; 29:e693-702.

8. Nowjack-Raymer RE, Sheiham A. Numbers of natural teeth, diet, and nutritional status in US adults. J Dent Res 2007; 86:1171-5.

9. Petersen PE, Yamamoto T. Improving the oral health of older people: the approach of the WHO Global Oral Health Programme. Community Dent Oral Epidemiol 2005; 33:81-92.

10. Bernabé E, Sheiham A. Tooth loss in the United Kingdom - trends in social inequalities: an ageperiod-and-cohort analysis. PLoS One 2014; 9:e104808.

11. Peres MA, Luzzi L, Peres KG, Sabbah W, Antunes JL, Do LG. Income-related inequalities in inadequate dentition over time in Australia, Brazil and USA adults. Community Dent Oral Epidemiol 2015; 43:217-25.

12. Guarnizo-Herreño CC, Tsakos G, Sheiham A, Marmot MG, Kawachi I, Watt RG. Austin Powers bites back: a cross sectional comparison of US and English national oral health surveys. BMJ 2015; 351:h6543.

13. Jagger DC, Sherriff A, Macpherson LM. Measuring socio-economic inequalities in edentate Scottish adults: cross-sectional analyses using Scottish Health Surveys 1995-2008/09. Community Dent Oral Epidemiol 2013; 41:499-508.

14. Moonesinghe R, Beckles GL. Measuring health disparities: a comparison of absolute and relative disparities. Peer J 2015; 24:e1438.

15. Shen J, Wildman J, Steele J. Measuring and decomposing oral health inequalities in an UK population. Community Dent Oral Epidemiol 2013; 41:481-9.

16. Wagstaff A, Paci P, van Doorslaer E. On the measurement of inequalities in health. Soc Sci Med 1991; 33:545-57. 
17. Murakami K, Hashimoto $\mathrm{H}$. Wealth-related versus income-related inequalities in dental care use under universal public coverage: a panel data analysis of the Japanese study of aging and retirement. BMC Public Health 2016; $16: 24$.

18. Cornejo-Ovalle M, Paraje G, Vásquez-Lavín F, Pérez G, Palència L, Borrell C. Changes in socioeconomic inequalities in the use of dental care following major healthcare reform in Chile, 2004-2009. Int J Environ Res Public Health 2015; 12:2823-36.

19. Devaux M, de Looper M. Income-related inequalities in health service utilisation in 19 OECD countries, 2008-2009. Paris: OECD Publishing; 2012. (OECD Health Working Papers, 58).

20. World Health Organization. Oral health surveys: basic methods. Geneva: World Health Organization; 1997.

21. Ministério da Saúde. Projeto SBBrasil 2003: condições de saúde bucal da população brasileira 2002-2003. Resultados principais. Brasília: Ministério da Saúde; 2004.

22. Roncalli AG, Silva NN, Nascimento AC, Freitas CHSM, Casotti E, Peres KG, et al. Aspectos metodológicos do Projeto SBBrasil 2010 de interesse para inquéritos nacionais de saúde. Cad Saúde Pública 2012; 28 Suppl:S40-57.

23. Ernstsen L, Strand BH, Nilsen SM, Espnes GA, Krokstad S. Trends in absolute and relative educational inequalities in four modifiable ischaemic heart disease risk factors: repeated cross-sectional surveys from the Nord-Trøndelag Health Study (HUNT) 1984-2008. BMC Public Health 2012; 12:266.

24. Holst D. Oral health equality during 30 years in Norway. Community Dent Oral Epidemiol 2008; 36:326-34.

25. Houweling TA, Kunst AE, Huisman M, Mackenbach JP. Using relative and absolute measures for monitoring health inequalities: experiences from cross-national analyses on maternal and child health. Int J Equity Health 2007; 6:15.

26. Krieger N, Williams DR, Moss NE. Measuring social class in US public health research: concepts, methodologies, and guidelines. Annu Rev Public Health 1997; 18:341-78.
27. Krieger N, Williams DR, Moss NE. Measuring social class in US public health research: concepts, methodologies, and guidelines. Annu Rev Public Health 1997; 18:341-78.

28. Davey Smith G, Hart C, Hole D, MacKinnon P, Gillis C, Watt G, et al. Education and occupational social class: which is the more important indicator of mortality risk? J Epidemiol Community Health 1998; 52:153-60.

29. Allin S, Masseria C, Mossialos E. Measuring socioeconomic differences in use of health care services by wealth versus by income. Am J Public Health 2009; 99:1849-55.

30. Ribeiro CG, Cascaes AM, Silva AE, Seerig LM, Nascimento GG, Demarco FF. Edentulism, severe tooth loss and lack of functional dentition in elders: a study in Southern Brazil. Braz Dent J 2016; 27:345-52.

31 de Andrade FB, Andrade FCD, Noronha K. Measuring socioeconomic inequalities in the use of dental care services among older adults in Brazil. Community Dent Oral Epidemiol 2017; 45:559-66.

32. Mullachery P, Silver D, Macinko J. Changes in health care inequity in Brazil between 2008 and 2013. Int J Equity Health 2016; 15:140.

33 Celeste RK, Nadanovsky P, Fritzell J. Trends in socioeconomic disparities in oral health in Brazil and Sweden. Community Dent Oral Epidemiol 2011; 39:204-12.

34. Antunes JL, Narvai PC. Dental health policies in Brazil and their impact on health inequalities. Rev Saúde Pública 2010; 44:360-5.

35. Peres MA, Barbato PR, Reis SC, Freitas CH, Antunes JL. Tooth loss in Brazil: analysis of the 2010 Brazilian Oral Health Survey. Rev Saúde Pública 2013; 47 Suppl 3:78-89.

36. Victora CG, Vaughan JP, Barros FC, Silva AC, Tomasi E. Explaining trends in inequities: evidence from Brazilian child health studies. Lancet 2000; 356:1093-8. 


\section{Resumo}

O estudo teve como objetivo avaliar as tendências nas desigualdades socioeconômicas na prevalência da dentição funcional entre idosos não institucionalizados no Brasil. O estudo usou dados das duas últimas pesquisas do Projeto SBBrasil, realizadas em 2003 e 2010. A dentição funcional foi definida como a presença de 20 ou mais dentes naturais, avaliada durante o exame clínico odontológico. A escolaridade foi usada como medida de nível socioeconômico. A desigualdade socioeconômica foi estimada com duas medidas complexas: o indice absoluto de desigualdade ou slope index of inequality (SII) e o relative index of inequality (RII). A prevalência da dentição funcional foi 10,8\% (IC95\%: 8,1-14,2) em 2003 e 13,6\% (IC95\%: 11,116,5) em 2010. A prevalência da dentição funcional aumentou significativamente com o aumento do nivel de escolaridade em ambos os anos. As desigualdades absolutas foram significativas para ambos os anos e permaneceram inalteradas entre 2003 e 2010. Nos dois anos da pesquisa, foi observada uma desigualdade relativa significativa na prevalência da dentição funcional. As desigualdades socioeconômicas na prevalência da dentição funcional entre idosos brasileiros persistiram significativamente entre as duas pesquisas nacionais de saúde oral.

Saúde Bucal; Desigualdades; Classe Social

\section{Resumen}

El objetivo de esta investigación fue evaluar las tendencias en inequidades socioeconómicas, respecto a la prevalencia de una dentición funcional entre adultos mayores, residentes en comunidades de Brasil. Se trata de un estudio transversal con datos de los dos últimos programas de Proyecto $S B B r a s i l$, en los que se realizaron encuestas $d u-$ rante los años 2003 y 2010. La dentición funcional se definió como la presencia de 20 o más dientes naturales y se evaluó durante un examen clínico del estatus de la dentadura. Se valoró la escolaridad como medida de clasificación socioeconómica. La inequidad socioeconómica se midió usando dos medidas complejas; slope index of inequality (SII) $y$ el relative index of inequality (RII). La prevalencia de la dentición funcional fue 10,8\% (IC95\%: 8,1-14,2) en 2003 y 13,6\% (IC95\%: 11,1-16,5) en 2010. La prevalencia de la dentición funcional se incrementó significativamente con el aumento del nivel de escolaridad en ambos años. Las inequidades absolutas fueron significativas para ambos años y permanecieron inalteradas entre $2003 y$ 2010. Se halló una inequidad relativa significativa en la prevalencia de la dentición funcional durante ambos años de la encuesta. Las inequidades socioeconómicas en la prevalencia de la dentición funcional entre adultos mayores en Brasil persistieron significativamente en ambas encuestas de salud bucal nacionales.

Salud Bucal; Desigualdades; Clase Social
Submitted on 20/Nov/2017

Final version resubmitted on 28/Apr/2018

Approved on 18/May/2018 